found possible to arrive at estimates of the size of certain of the plant viruses. The relationship between the insect carrier and the virus is also under investigation, and some striking results have been obtained slready in regard to the connexion between degree of infection, season, and length of feeding times on the infected plant.

In addition to discussions of the various investiga- tions in progress, the report contains a wealth of other material, such as the farm report, also notes on the insect pests and fungus diseases at Rothamsted and Woburn. Many branches of agricultural science gain from the information given in this report; the close connexion between laboratory and farm, together with the carefully planned field trials, give a high value to all the data supplied.

\title{
Precision Methods of Measuring Stellar Radiation
}

$\mathrm{I}^{\mathrm{N}}$ a communication, dated October 17, from the Smithsonian Institution, Washington, an account is given of experiments made by Dr. Charles G. Abbot, secretary of the Institution and Mr. W. H. Hoover, of the Smithsonian staff, at the Mount Wilson Observatory of the Carnegie Institution at Washington, on the total energy radiated by distant stars in narrow wave-length bands. For the measurement of electric current they used a galvanometer which was twenty times as sensitive as any instrument of this sort used in the past. A magnetic shield for this very sensitive galvanometer was made for the Institution by the late Dr. Elihu Thomson, of the General Electric Company, one of the world's foremost inventors of electrical devices. The galvanometer itself was made at the Institution and will detect a current variation of $1 / 10^{13}$ of an ampere.

The galvanometer is attached to a thermocouple, the standard astronomical instrument for measuring extremely minute amounts of heat energy. The thermocouple used by Dr. Abbot and Mr. Hoover is a more sensitive, and at the same time a more robust instrument, than any hitherto used.

The efficiency of the new devices has just been tested in California, using the Carnegie Institution's 100-inch telescope, with encouraging results. Dr. Abbot and Mr. Hoover measured with a high degree of precision the relative energies in narrow bands of the spectra of a number of the brighter stars. The total heat which reaches the earth from all the thousands of millions of stars of the Milky Way is extremely small. If the earth depended on this heat alone, the temperature would be approximately $-270^{\circ} \mathrm{C}$. Many individual stars in the galaxy are many times hotter than the sun, but their radiation is soon dissipated in the immensity of space.

Astronomers have had for many years instruments sufficiently delicate to measure the total radiation of several of the planets of the solar system. It has also been possible within the past few years to measure the total radiation of selected single stars. The aggregate light of such a star is focused on the thermocouple, essentially a junction of two wires made of different kinds of metal, through which an electric current is caused to flow by the minute rise of temperature produced by the stellar radiation, any variation in the temperature of the junction produces an alteration in the current measured by the galvanometer. The amount of the radiation energy necessary to produce a change in the current, the distance of the star and the rate of dissipation of stellar radiation in space being known, it is possible to calculate the actual heat from the star itself.
Dr. Abbot and Mr. Hoover have gone a step farther. In the radiation of almost every star are to be found all the elements of the spectrum from the infra-red to the ultra-violet. Actually the proportions of infra-red, visible light and ultra-violet differ enormously in the radiation of different classes of stars. It was the problem of measuring the approximate amount of radiation from a star in different narrow bands of wave-lengths that the Smithsonian astronomers set themselves. This task required the most precise measurements ever attempted.

Experience for the task was drawn from two sources. A division of the Institution has been engaged for years in measuring the precise effects on plants of illumination from different wave-lengths of light. This required further development of an instrument known as the Christiansen filter to segregate narrow bands of wave-lengths from the light and heat of an arc lamp, and also of improve. ment of the thermocouple. There seems little connexion between oat seedlings growing in boxes and giant stars a 1000 light-years away, but all Nature seems tied together so inextricably that the development of this technique connects the one inextricably with the other. The other source was the work of the Smithsonian Institution's observatories set up on distant mountain tops in various parts of the world, the work of which is to make very precise measurements daily of minute variations in the radiation of the sun. This has called for more and more responsive heat-measuring instruments.

Dr. Abbot began the present work in 1923, using an instrument called the radiometer prepared for him by the late Dr. E. F. Nichols. In 1928 he returned to the task, using a fly-vane radiometer of his own construction in which the sensitive element was a small piece cut from the wing of a house fly. $\mathrm{He}$ has hoped to continue the experiments ever since with instrumental improvements giving greater sensitiveness. A point has now been reached where the measurement of the energy in narrow stellar wave bands can be made with high accuracy.

It is possible, however, that much greater re. sponsiveness will be attained within the next two years, before the 200 -inch telescope, with which it is planned to carry out the main programme of measurements, is set up at Mount Palomar in California. It may be possible to improve the thermocouple, to eliminate the element of drift due to the sensitivity of the two joined elements.

The last measurements made by Dr. Abbot were at Mount Wilson ten years ago. At that time the greatest swing of the recording light spot that could be attained was only about one millimetre. This year 
Mr. Hoover easily obtained swings of twenty millimetres, which is equivalent to a twentyfold preciseness in his measurements.

Far-reaching results may be attained with the new technique. A means is now at hand of determining with considerable accuracy temperatures, depths and compositions of the atmospheres of stars, and this will make possible more accurate estimates of the size and nature of stellar bodies.

\section{Economics of Industry}

A RISING out of the Conference held in 1937 by the International Industrial Relations Institute, when the theme was productivity and standards of living as influenced by industrial relations, the Institute has arranged a series of publications, the I.R.I. Social Economic Series, to present the results of its studies. Two of these have now appeared, the first by A. Carrillo on "Mexico's Resources for Livelihood" including a general introduction to the series on the world's natural resources and standards of living (Mexico's Resources for Livelihood : a Study of the Influence of Foreign Ownership. By Alejandro Carrillo. Pp. 34. The Hague and New York: International Industrial Relations Inst., 1938. 25 cents).

This introduction outlines the field opened up, including an analysis of the distribution of the world's raw materials and a survey of the hitherto abortive efforts to deal with the problem through international action. The implications of power production for economic organization are also considered, and in addition to summaries of the main arguments in the papers submitted to the 1937 Conference a number of suggestions for immediate action are outlined. Mr. Carrillo's special study gains further interest in view of the expropriation of oil by the Mexican Government since the paper was written, and it facilitates appreciation of the situation in Mexico and the important moral achievements of the revolution.

The second paper, by M. Yergan on gold and poverty in South Africa, is a study of economic organization and standards of living; it is yet another indictment of the labour policy pursued in South Africa with its deliberate exploitation of native labour as part of the natural resources of the country (Gold and Poverty in South Africa: a Study of Economic Organisation and Standards of Living. By Max Yergan. Pp. 24. The Hague and New York: Intemational Industrial Relations Inst., 1938. 15 cents). The importance of workers' living standards as an element in the problem of raw materials is again emphasized, and while the report recognizes that the errors and dangers of the policy hitherto pursued are now perceived by an increasing body of European opinion, the material it presents overthrows a conception of trusteeship under the conditions which prevail in South Africa. The importance of encouraging and co-operating with all those in South Africa, whether African or European, who are aware of the dangers and real needs, and striving to meet them, is emphasized, as well as the need for strenuous efforts to eradicate the hates and prejudices which repression and exploitation have developed within the ranks of both Africans and Europeans.

\section{Science News a Century Ago}

Temperature of the Crust of the Earth

WITH the assistance of the British Association, J. D. Forbes in 1837-38 made determinations of the temperature of the soil in the neighbourhood of Edinburgh, the results of his experiments being given in a paper read to the Royal Society of Edinburgh on December 3, 1838, entitled "Discussion of One Year's Observations of Thermometers sunk to different Depths in different localities in the Neighbourhood of Edinburgh".

The principal purpose of the experiments undertaken by Forbes was to ascertain the progress of solar heat in the crust of the earth, and had no immediate reference to the question of central heat. With the view of rendering the observations comparable with those at Paris and Brussels, the lowest thermometers had their bulbs 24 French feet ( $=25 \cdot 6$ English) below the surface. Other thermometers were placed at depths of 12, 6 and 3 French feet. The observations were begun in February 1837 and were continued weekly.

The three stations for the experiments were at the Observatory, Calton Hill, in the sand in the Experimental Garden and in the compact coal formation sandstone of Craigleith Quarry. Among other results obtained, Forbes found that at the greatest depths the annual range temperature was $1 \cdot 45^{\circ} \mathrm{F}$. at the Observatory, $2 \cdot 1^{\circ} \mathrm{F}$. at the Garden and $4 \cdot 1^{\circ} \mathrm{F}$. at the Quarry.

\section{Footprints of the Chirotherium}

AT a meeting of the Geological Society on December 5,1838 , one of the communications was "An Account of the Footsteps of the Chirotherium and five or six other unknown animals lately discovered in the quarries of Storeton Hill, between the Mersey and the Dee". The communication was made by the Natural History Society of Liverpool and was accompanied by drawings by J. Cunningham. In 1834 there were discovered in several quarries at the village of Hessburg near Hildberghausen, casts in a grey quartzose sandstone, resembling to some extent a human hand, and for which Prof. J. J. Kaup proposed the provisional name of Chirotherium. In June 1838, similar casts were discovered in the Storeton Hill quarries. The Natural History Society of Liverpool appointed a committee to report on these.

The red sandstone of the peninsula of Wirral may be divided into three layers : a lower consisting of a red or variegated sandstone and conglomerate, a middle of white and yellow sandstone, and an upper or red or variegated marl and sandstone containing pebbles of quartz. It is the middle division which was worked at the quarry. The strata there are of unequal thickness, and are separated by thin seams of whitish clay. The casts appear to have been moulded in impressions made by the Chirotherium and other animals walking over the clay.

The animal had been tracked by its marks $16 \mathrm{ft}$. on one stone. Although the footsteps of the Chirotherium are the most prominent there are slabs covered by raised casts apparently made by tortoises and saurian reptiles. 